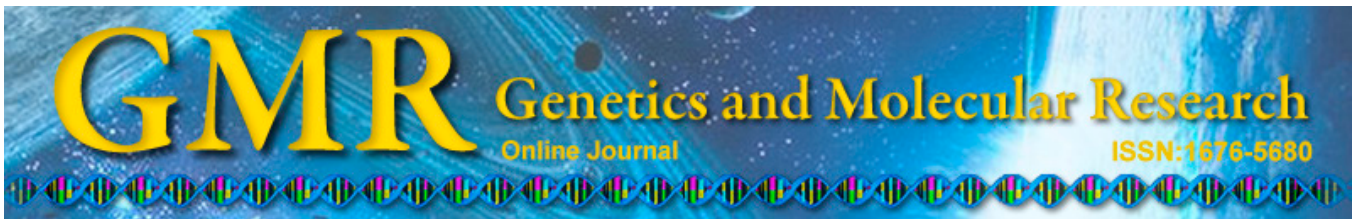

\title{
Generation of bovine (Bos indicus) and buffalo (Bubalus bubalis) adipose tissue derived stem cells: isolation, characterization, and multipotentiality
}

\author{
R.V. Sampaio ${ }^{1,2,3}$, M.R. Chiaratti ${ }^{2,4}$, D.C.N. Santos ${ }^{1}$, F.F. Bressan ${ }^{2}$, \\ J.R. Sangallii, ${ }^{2,3}$ A.L.A. Sá ${ }^{1}$, T.V.G. Silva ${ }^{1}$, N.N. Costa ${ }^{1}$, M.S. Cordeiro ${ }^{5}$, \\ S.S.D. Santos ${ }^{1}$, C.E. Ambrosio ${ }^{2}$, P.R. Adona ${ }^{6}$, F.V. Meirelles ${ }^{2}$, M.S. Miranda ${ }^{1}$ \\ and O.M. Ohashi ${ }^{1}$ \\ ${ }^{1}$ Departamento de Biologia, Instituto de Ciências Biológicas, \\ Universidade Federal do Pará, Belém, PA, Brasil \\ ${ }^{2}$ Departamento de Medicina Veterinária, \\ Faculdade de Zootecnia e Engenharia de Alimentos, \\ Universidade de São Paulo, Pirassununga, SP, Brasil \\ ${ }^{3}$ Departamento de Cirurgia, Faculdade de Medicina Veterinária e Zootecnia, \\ Universidade de São Paulo, Pirassununga, SP, Brasil \\ ${ }^{4}$ Departamento de Genética e Evolução, \\ Universidade Federal de São Carlos, São Carlos, SP, Brasil \\ ${ }^{5}$ Instituto Federal de Ciência e Tecnologia do Pará, Belém, PA, Brasil \\ ${ }^{6}$ Universidade Norte do Paraná, Londrina, PR, Brasil \\ Corresponding author: R.V. Sampaio \\ E-mail: sampaiorv@gmail.com
}

Genet. Mol. Res. 14 (1): 53-62 (2015)

Received May 21, 2014

Accepted December 6, 2014

Published January 15, 2015

DOI http://dx.doi.org/10.4238/2015.January.15.7

\begin{abstract}
Adult stem cells are known for their plasticity and their potential to differentiate into several different cell types; these characteristics have implications for cell therapy and reproductive biotechnologies. In this study, we report on the isolation and characterization of mesenchymal stem cells (MSC) derived from bovine and buffalo adipose tissue. Cells isolated using enzymatic digestion of
\end{abstract}


bovine and buffalo adipose-tissue biopsy samples were grown in vitro for at least 15 passages, verifying their capacity to proliferate. These cells were also subjected to immunophenotypic characterization for the presence of CD90, CD105, and CD79, and the absence of CD45, CD34, and CD73, which are positive and negative markers of MSC, respectively. To prove their multipotency, the cells were induced to differentiate into three different cell types, chondrocytes, osteoblasts, and adipocytes, which were stained with tissue-specific dyes (Chondrogenic-Alcian Blue, Osteogenic-Alizarin Red, and Adipogenic-Oil-Red O, respectively) to confirm differentiation. Gene expression analysis of pluripotency-related genes was also conducted. Our results suggest that adipose tissue from bovines and buffalos can be used as a source of MSC, making adipose tissue-derived cells an interesting option for cell therapy and regenerative medicine. Additionally, these findings have implications for reproductive biotechnology because the use of MSC as nuclear donors has been linked to an increase in the efficiency of nuclear transfer.

Key words: Cell therapy; Mesenchymal stem cells; Adipose tissue; Cattle; Buffalo

\section{INTRODUCTION}

Adult stem cells are known for their plasticity and their potential to differentiate into several different cell types (i.e., multipotency) (Bjornson et al., 1999). This multipotency has important implications for many fields of medicine as these cells could potentially be used for cell therapy in humans and animals. For instance, stem cell-based therapies may be used to regenerate compromised tissue, reestablishing its function and even reversing a patient's physical deficiency (Karp and Leng Teo, 2009). Although only stem cells derived from embryos in the early stages of development [embryonic stem cells (ESCs)] are thought to be totipotent, adult individuals also retain cells that are able to differentiate into many cell types; the origin of the cells determines the cell types (Passier and Mummery, 2003).

Adult stem cells, such as mesenchymal stem cells (MSC), represent a major source of multipotent cells, which are progenitors of cells from specific tissues (Pittenger et al., 1999). For instance, adipose-derived stem cells (ASC) are fibroblast-like cells that are capable of both supporting hematopoiesis and differentiating into adipocytes, fibroblasts, myoblasts, chondrocytes, and osteoblasts (Zuk et al., 2002). Moreover, although ASC are of mesodermal origin, data have shown they are capable of transdifferentiating into neural cells as well (SanchezRamos et al., 2000). Despite their limited differentiation potential compared to ESCs, MSC have drawn much interest from researchers for both basic and applied studies involving their multipotency (Bjornson et al., 1999; Passier and Mummery, 2003; Karp and Leng Teo, 2009).

Adipose-derived stem cells can be easily retrieved in large amounts from the adipose tissue of adult individuals and cultured in vitro, making use of these cells a viable option for further applications, such as autologous transplants (Gimble, 2003; McCoy et al., 2008). Compared to bone marrow, which represents another major source of MSC, harvesting of fat cells has the advantage of being less invasive and producing more stem cells (Zuk et al., 2002; Rodriguez et al., 2005). In addition, harvesting cells from adipose tissue results in in vitro 
cultures composed almost exclusively of MSC, whereas bone marrow-derived cultures have a less homogenous cell population (Zuk et al., 2002; Rodriguez et al., 2005; Zhu et al., 2008).

In addition to the importance of MSC in human cell therapies, these cells are also an extremely valuable tool for both basic science and livestock production because it has been hypothesized that the use of MSC as nuclear donors may lead to an increase in somatic cell nuclear transfer (SCNT) efficiency. MSC are more undifferentiated (or at least still contain trophic factors) than other somatic cells (i.e., granulosa cells and fibroblasts) commonly used in SCNT (Faast et al., 2006; Jin et al., 2007). Moreover, evidence indicates that the use of MSC as nuclear donors in SCNT increases the embryonic developmental rates of cloned domestic animals, such as pigs and bovines (Colleoni et al., 2005; Lee et al., 2010). The MSC used in those studies were derived from tissues, such as bone marrow, which cannot be sourced as easily as adipose tissue, implicating practical limitations.

Harvesting, isolation, and in vitro culture of ASC has not been well established for some species. Although there are protocols for the isolation of ASC from many species, including humans and equines (Zuk et al., 2002; de Mattos Carvalho et al., 2009), to our knowledge, there is no published data describing such procedures for large ruminants (i.e., bovines and buffalos). Large ruminants, such as bovines, have been suggested as a relevant model system for humans (Miziara et al., 2004; Berg et al., 2011). Moreover, new methods that increase SCNT efficiency in bovine have significant implications for livestock (Meirelles et al., 2010). Therefore, the aim of this study was to isolate, characterize, and investigate the multilineage differentiation potential of bovine (Bos indicus) and buffalo (Bubalus bubalis) MSC sourced from adipose tissue of adult animals.

\section{MATERIAL AND METHODS}

Unless otherwise stated, plastic ware was purchased from Corning Inc. (Corning, NY, USA) and chemicals from Sigma-Aldrich Chemical Co. (St. Louis, MO, USA). In vitro experimental procedures were performed in humidified incubators maintained at $38.5^{\circ} \mathrm{C}$ in air with $5 \%$ $\mathrm{CO}_{2}$. The present study complied with the International Guiding Principles for Biomedical Research Involving Animals, as issued by the Council for the International Organizations of Medical Sciences. Five and three isolations were performed for bovine and buffalo ASC, respectively.

\section{Isolation and culture of ASC}

Adipose tissue was collected from the base of the tail for ASC isolation due to the absence of large vessels and the accessibility and availability of material at that location. Epidural anesthesia was administrated with $2 \%$ lidocaine chlorhydrate (Anestésico L, Eurofarma, São Paulo, SP, Brazil) to adult bovines (B. indicus) and buffalos (B. bubalis) before trimming and carefully cleaning the base of the tail. Then, an incision of $3-5 \mathrm{~cm}$ in length was made at the base of the tail for retrieval of approximately $5 \mathrm{~g}$ of adipose tissue, which was extensively washed in cold saline solution supplemented with $400 \mu \mathrm{g} / \mathrm{mL}$ streptomycin (Gibco BRL, Grand Island, NY, USA) and 400 units/mL penicillin (Gibco BRL). Next, the tissue was minced for 30 min with a sterile scalpel blade on a plastic dish and digested with $0.001 \%$ type I collagenase (Gibco BRL) diluted in Alpha Minimum Essential Medium ( $\alpha$-MEM; Gibco BRL) with 100 $\mu \mathrm{g} / \mathrm{mL}$ streptomycin, $100 \mathrm{U} / \mathrm{mL}$ penicillin, and $50 \mu \mathrm{g} / \mathrm{mL}$ nystatin. After digestion for $3 \mathrm{~h}$ at $38.5^{\circ} \mathrm{C}$, collagenase activity was neutralized by the addition of an equal volume of $\alpha$-MEM 
containing $15 \%$ fetal bovine serum (FBS; Gibco BRL), $83.4 \mu \mathrm{g} / \mathrm{mL}$ amikacin sulfate, and 50 $\mu \mathrm{g} / \mathrm{mL}$ nystatin. The treated tissue was centrifuged at $300 \mathrm{~g}$ for $10 \mathrm{~min}$, and the pellet was resuspended in $\alpha$-MEM supplemented with $15 \%$ FBS, $83.4 \mu \mathrm{g} / \mathrm{mL}$ of amikacin sulfate, and $50 \mu \mathrm{g} /$ $\mathrm{mL}$ of nystatin. A second centrifugation step was performed at $300 \mathrm{~g}$ for $10 \mathrm{~min}$, and the pellet was resuspended and plated on $35-\mathrm{mm}$ plastic dishes with the same culture medium. Cells were maintained in incubators, and the culture medium was replaced every two days, except for the first medium change that was performed $24 \mathrm{~h}$ after cell culture.

Non-adherent cells, including hematopoietic cells, were removed after the first medium change because they are less capable of attaching to the surface of a plastic dish. When cells reached $60-75 \%$ confluence, they were trypsinized (Tryple Express, Gibco BRL) and plated on news dishes in $\alpha$-MEM with $15 \%$ FBS and $83.4 \mu \mathrm{g} / \mathrm{mL}$ amikacin sulfate. Cells were grown for 15 and 25 passages for bovines and buffalos, respectively. Cells were plated at a density of $3 \times 10^{4}$ or $4 \times 10^{4}$ cells per $35-\mathrm{mm}$ plate and replated every two and three days for bovines and buffalos, respectively. Cell doubling time was estimated in triplicate as described by Raoufi et al. (2011).

\section{Immunophenotypic characterization}

Cells were characterized by the presence of CD105 (endoglin), CD90 (Thy-1), and CD73, surface markers exclusive to MSC, and also by the absence of CD34, CD45, and CD79A, which are markers that are exclusive to hematopoietic cells, as previously reported (Dominici et al., 2006).

Primary antibodies were purchased from Santa Cruz Biotechnology (Santa Cruz, CA, USA), Alexa488- and Alexa594-conjugated secondary antibodies were purchased from Invitrogen (Carlsbad, CA, USA), and the Cy3-conjugated secondary antibody was purchased from Jackson Immunoresearch Laboratories (West Grove, PA, USA). Cells were plated on coverslips after 1 or 2 passages and cultured for two days. They were then washed in phosphate buffer saline (PBS) and fixed in 4\% paraformaldehyde in PBS for $15 \mathrm{~min}$ at room temperature and washed again in PBS. Next, cells were incubated in 5\% bovine serum albumin in PBS for $15 \mathrm{~min}$ at room temperature and overnight at $4{ }^{\circ} \mathrm{C}$ with each of the following antibodies diluted (1:50) in PBS: CD105, CD90, CD73, CD34, CD45, or CD79. Cells incubated without primary antibodies served as negative controls for all assays. Cells were then extensively washed in PBS and incubated for $45 \mathrm{~min}$ at room temperature with Alexa488- and Alexa594-conjugated secondary antibodies diluted 1:50 or Alexa488-, Alexa594- or Cy3-conjugated anti-mouse antibodies diluted 1:200. Cell nuclei were stained with $10 \mu \mathrm{g} / \mathrm{mL}$ Hoechst 33342 in PBS for $15 \mathrm{~min}$ at room temperature. Finally, cells were washed, mounted on microscope slides, and analyzed on a fluorescence microscope at 200X magnification (Nikon Eclipse TE 300, Nikon Instruments Inc., Tokyo, Japan). Negative controls were analyzed to account for secondaryantibody background due to unspecific staining of cells.

\section{In vitro differentiation}

Cells were tested for their potential to differentiate into osteogenic, adipogenic, and chondrogenic cells, as previously reported (Zuk et al., 2002). For osteogenic differentiation, $3 \times 10^{4}$ cells that had been passaged 3 to 5 times were plated on plastic dishes and cultured overnight. The culture medium was then replaced with $\alpha$-MEM with $2 \%$ FBS, $0.1 \mu \mathrm{M}$ dexamethasone, $50 \mu \mathrm{M}$ ascorbic acid-2-phosphate, $10 \mathrm{mM} \beta$-glycerophosphate, and $83.4 \mu \mathrm{g} / \mathrm{mL}$ 
amikacin sulfate. These cells were cultured in this medium for three weeks. For adipogenic differentiation, cells were cultured for three weeks as described previously but using D-MEM (Gibco BRL) with $2 \% \mathrm{FBS}, 1 \mu \mathrm{M}$ dexamethasone, $10 \mu \mathrm{M}$ insulin, $100 \mu \mathrm{M}$ indomethacin, 0.5 $\mathrm{mM} 3$-isobutyl-1-methylxanthine, and $83.4 \mu \mathrm{g} / \mathrm{mL}$ amikacin sulfate. For chondrogenic differentiation, cells were plated as described above and cultured for 3 weeks in $\alpha$-MEM, 6.25 $\mu \mathrm{g} / \mathrm{mL}$ insulin, $10 \mathrm{ng} / \mathrm{mL}$ TGF- $\beta 1,50 \mathrm{nM}$ ascorbic acid-2-phosphate, and $83.4 \mu \mathrm{g} / \mathrm{mL}$ amikacin sulfate. Cells plated as described above but cultured in regular culture medium ( $\alpha$-MEM with $15 \%$ FBS and $83.4 \mu \mathrm{g} / \mathrm{mL}$ amikacin sulfate) were used as negative controls. For all 3 differentiation protocols, the culture medium was changed and the cells were monitored for morphological changes every 2 days.

\section{Differentiation analysis}

To confirm whether the cells had differentiated after exposure to each of the differentiation protocols, the cells were washed twice with PBS, fixed in $4 \%$ paraformaldehyde in PBS for $15 \mathrm{~min}$ at room temperature, washed again in PBS and stained, as described below. Briefly, for osteogenic differentiation, calcium deposition was visualized by staining the cells with $2 \%$ Alizarin Red S in water, pH 4.1, as previously reported (Yamamoto et al., 2007). For adipogenic differentiation, intracellular accumulation of lipid-enriched vacuoles was visualized by staining of the cells with $1.25 \%$ Oil Red O in 30\% isopropanol for 10 min at room temperature, followed by washing with $60 \%$ isopropanol (Cheong et al., 1993; Zuk et al., 2002). For chondrogenic differentiation, the presence of proteoglycans in the cells was verified by staining of the cells with $1 \%$ Alcian Blue in $3 \%$ acetic acid, $\mathrm{pH} 2.5$, as previously reported (Zuk et al., 2002). Stained cells were visualized under an inverted microscope at 400X magnification (Nikon Eclipse 50i, Nikon Instruments Inc.).

\section{Gene expression analysis of pluripotency-related genes}

Cells were submitted to semi-quantitative gene expression analysis of NANOG, OCT4 and SOX2 using GAPDH as a reference gene (Table 1). Briefly, RNA was extracted from cell cultures using Trizol reagent (Life Technologies Inc., Grand Island, NY, USA) following the manufacturer protocol and with the addition of $5 \mathrm{mg} / \mathrm{mL}$ linear acrylamide (Life Technologies). Samples were treated with DNAse I and cDNA was produced following the High Capacity cDNA Reverse Transcription kit protocol (Applied Biosystems) and transcripts were amplified using qPCR and the Power SYBR Green reagent (Applied Biosystems). Primers were used at $400 \mathrm{nM}$ at an annealing temperature of $60^{\circ} \mathrm{C}$ and over 40 cycles.

\section{Table 1. Primers used to amplify genes from mesenchymal stem cells of bovine and buffalo.}

\begin{tabular}{ll}
\hline Gene & Oligonucleotides $\left(5^{\prime} \rightarrow 3^{\prime}\right)($ up/down) \\
\hline GAPDH & GGCGTGAACCACGAGAAGTATAA \\
OCT4 & CCCTCCACGATGCCAAAGT \\
NANOG & CAGGCCCGAAAGAGAAAGC \\
SOX2 & CGGGCACTGCAGGAACA \\
& CCCTCGACACGGACACTGT \\
& GACTGTCCTGAATAAGCAGATCCA \\
\hline
\end{tabular}


Standard curves were performed from a pool of 50 parthenogenetic bovine blastocysts. The efficiency of each gene was analyzed and cDNA was normalized and quantified as described by Livak and Schmittgen (2001).

\section{RESULTS}

Bovine and buffalo ASC adhered to plastic dishes shortly after plating and showed a fibroblast-like morphology with a single nucleus (Figure 1a and b).

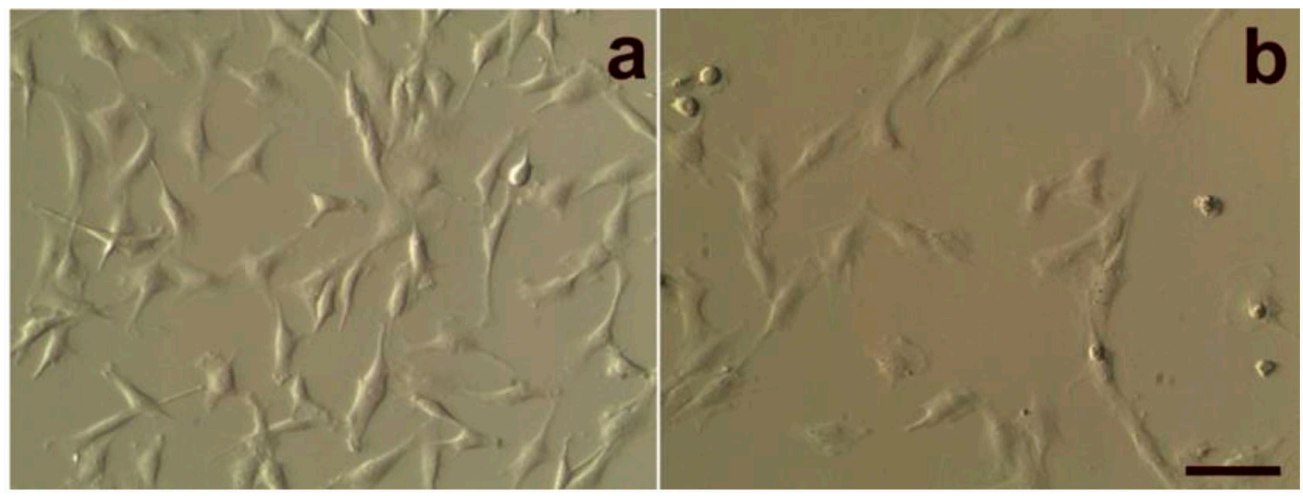

Figure 1. Bovine (a) and buffalo (b) adipose-derived stem cells. Scale bar $=50 \mu \mathrm{m}(200 \mathrm{X})$.

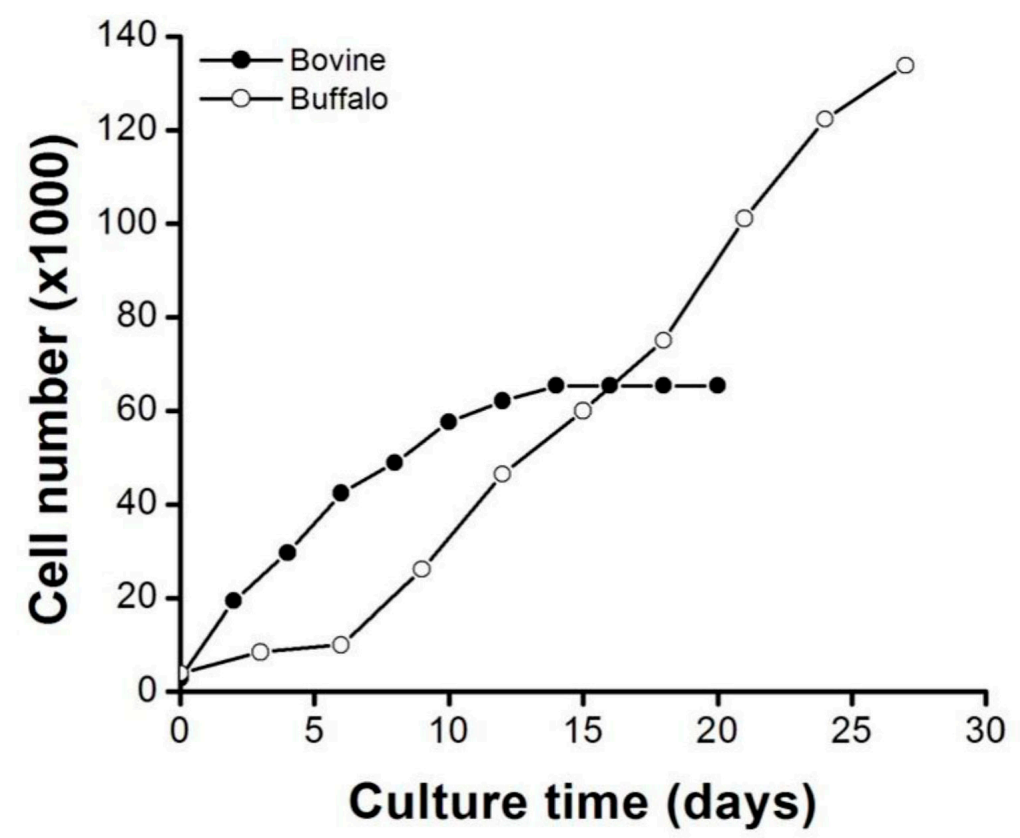

Figure 2. Growth curves of bovine (filled circle) and buffalo (open circle) adipose-derived stem cells (ASC). Bovine and buffalo ASC were replated every 48 or $72 \mathrm{~h}$, respectively. 
During the first and second cell passages, buffalo ASC grew slowly, but during the next 9 passages their growth became faster $(31 \pm 1.3 \mathrm{~h}$ doubling time), with buffalo ASC reaching the plateau phase after 72 days of culture ( 25 cell passages). Bovine ASC grew exponentially from the first cell passage until the ninth $(30 \pm 1.9 \mathrm{~h}$ doubling time $)$ but reached the plateau phase earlier, after 28 days of culture ( 15 cell passages). As a result, the final amount of buffalo ASC was almost 4 fold higher than that of bovine ASC.

As expected, MSC did not express genes related to pluripotency. For characterization of ASC using immunocytochemistry, we provided a panel with specific positive and negative markers for both bovine and buffalo ASC. Cells from both bovines and buffalos were found to be positive for CD105, CD90, CD73 (Figure 3a-c and a'-c'), which are exclusively found in MSC. Conversely, the negative MSC markers, CD34, CD45, and CD79, did not stain bovine or buffalo ASC (Figure 3d-f and d'-f'), indicating an absence of contaminant hematopoietic cells in the culture. No difference in immunocytochemical staining was observed between bovines and buffalos. The presence of markers specific for MSC in bovine and buffalo cells supports the conclusion that these cells originated from ASC.

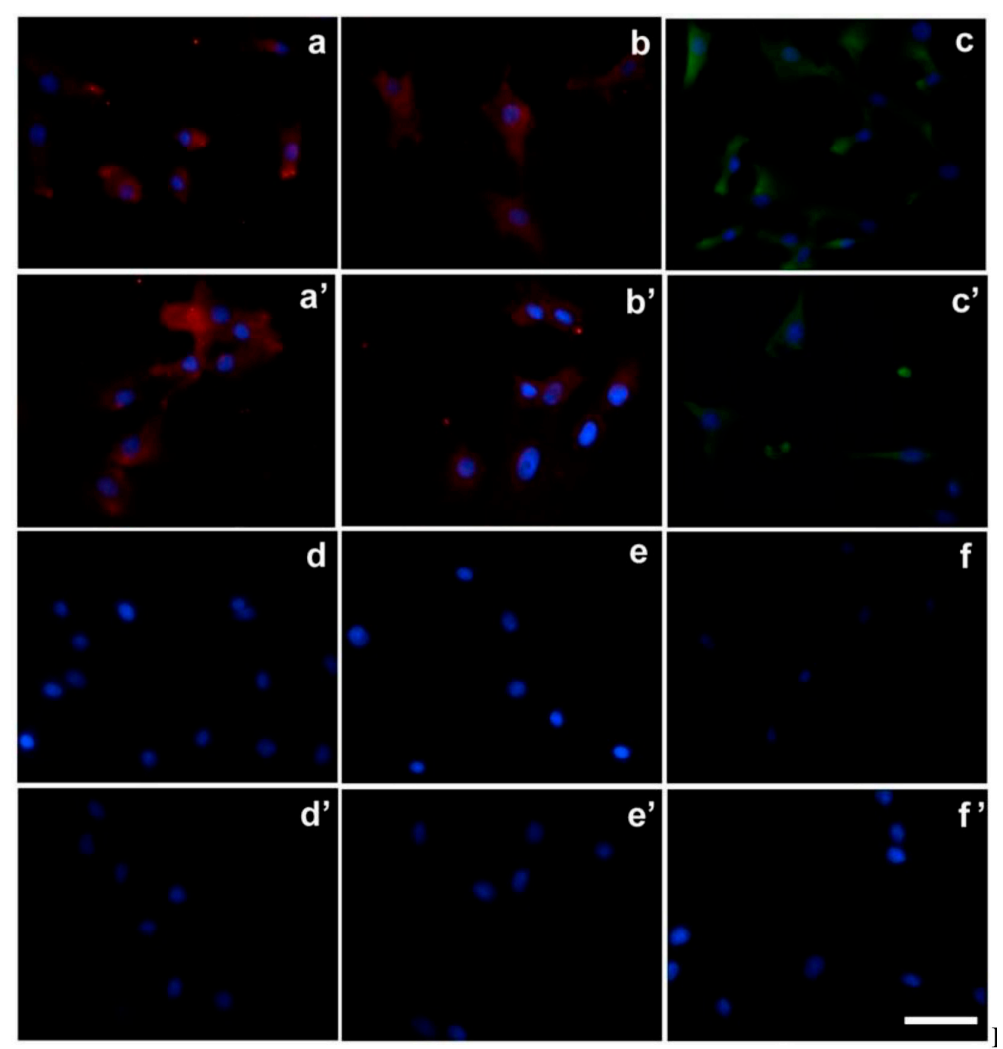

Figure 3. Immunophenotypic characterization of adipose-derived stem cells (ASC). Bovine (a-f) and buffalo (a'f') ASC were analyzed for the presence of positive mesenchymal stem-cell markers, CD105 (a and a'), CD90 (b and b') and CD73 (c and c'), and negative mesenchymal stem-cell markers, CD 34 (d and d'), CD45 (e and e'), and CD79A (f and f'). These markers are indicated in red or green. All cells were also stained with Hoechst 33342 (indicated in blue), which exclusively dyes the cell nucleus. Scale bar $=25 \mu \mathrm{m}(400 \mathrm{X})$. 
When the multilineage differentiation potential of ASC was tested in vitro, standard morphological changes were observed in the cells depending on the differentiation protocol and time of exposure. Morphological changes were first seen within one week of treatment. It is worthwhile to note that morphological changes in response to differentiation treatments were seen earlier in cells derived from buffalos than those derived from bovines. These morphological changes included lipid accumulation due to differentiation into adipocytes and increased cell size due to chondrogenic and osteogenic differentiation. Cells subjected to an osteogenic differentiation protocol increased in size after 1 week of treatment. These cells stained positively for Alizarin Red S until the third week of treatment, indicating mineralized matrix deposition (Figure 4a and a').
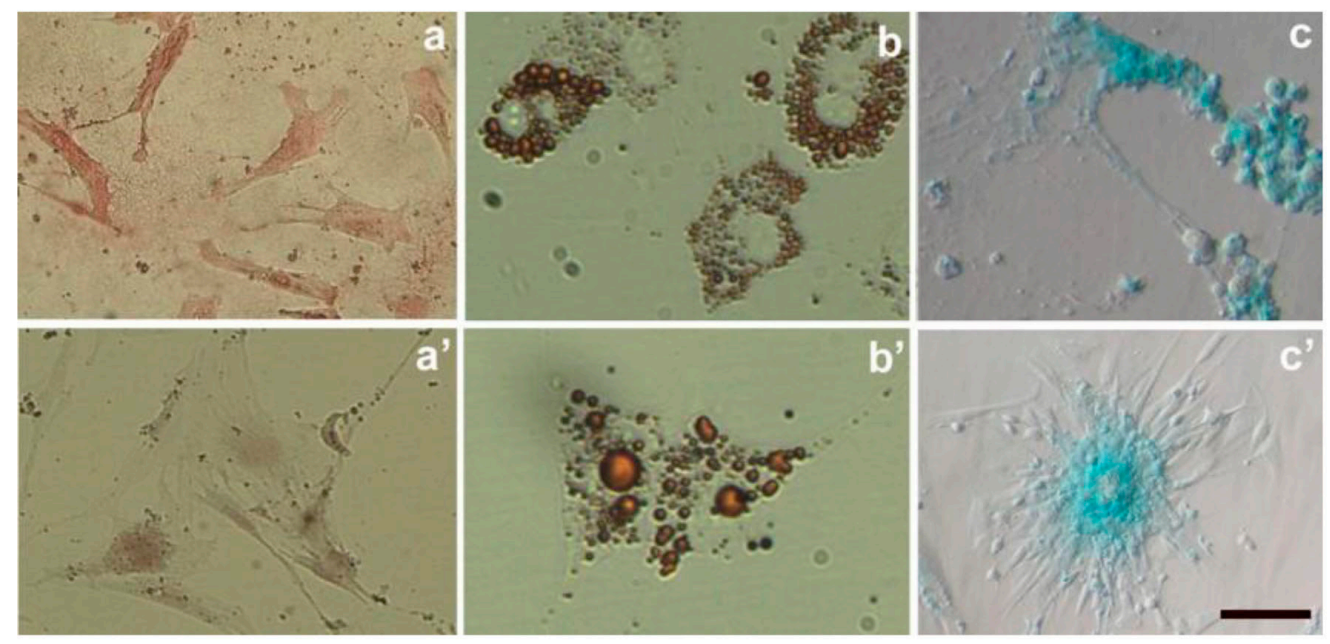

Figure 4. Differentiation analysis of adipose-derived stem cells (ASC). Osteogenic (a and a'), adipogenic (b and $\left.b^{\prime}\right)$, and chondrogenic (c and c') differentiation of bovine (a-c) and buffalo (a'-c') ASC. Scale bar $=50 \mu \mathrm{m}(200 \mathrm{X})$.

Increased cell size was also observed in cells subjected to an adipogenic differentiation protocol, and these cells began to develop lipid-like vesicles within 1 week of treatment. After 2 to 3 weeks, these vesicles filled most of the cytoplasm and stained positively for Oil Red-O (Figure $4 b$ and b'). Finally, glycosaminoglycan-rich matrixes were found in cells subjected to a chondrogenic differentiation protocol after 1 to 2 weeks of treatment, as indicated by Alcian Blue staining (Figure $4 \mathrm{c}$ and $\mathrm{c}^{\prime}$ ). In summary, these findings support the feasibility of derivation of ASC from bovine and buffalo adipose tissues.

\section{DISCUSSION}

Previous reports have described the isolation of MSC from several species and tissues; however, to our knowledge, isolation of ASC from bovines and buffalos has not yet been done (Bosnakovski et al., 2005; Rodriguez et al., 2005; Yamamoto et al., 2007; Neupane et al., 2008; de Mattos Carvalho et al., 2009; Bourzac et al., 2010; Raoufi et al., 2011). The ASC we isolated from bovines and buffalos in this study display similar characteristics (i.e., cell 
morphology, doubling time, and multilineage differentiation potential) to those previously reported for MSC isolated from other species and tissues. The ASC origin of cells derived from bovine and buffalo adipose tissue is also indicated by the presence of specific immunocytochemical markers of MSC (Dominici et al., 2006). Moreover, adipose tissue is easily accessible for the isolation of MSC without hematopoietic cell contamination. A large number of ASC (i.e., 100,000 cells) can be derived, after only a few days of culturing, from a small biopsy of adipose tissue (i.e., $5 \mathrm{~g}$ ), enabling the use of this method to generate MSC for largescale downstream applications (Zhu et al., 2008).

Emerging cell-based therapies may benefit from a source of autologous multipotent stem cells. Adipose tissue represents a potential source of adult stem cells for tissue engineering applications, such as cell-based therapies or NT. However, additional studies and clinical trials need to be performed before these therapies become available in humans. Such studies include animal-based studies, which could be conducted in bovines because they have been recognized as a valuable model for such purposes (Chacko and Ranganathan, 2009; Berg et al., 2011). Compared to mouse models, bovine models are genetically closer to humans (Miziara et al., 2004) and have a longer lifespan potential (Clark et al., 2003). In addition, studies on bovines are ethically more acceptable than studies on non-human primates. In this context, ASC from bovine and buffalo adipose tissue provide a relevant model for basic and applied studies involving human stem cells. However, previous reports have shown a beneficial effect on SCNT efficiency when using MSC as nuclear donors compared to somatic cells, such as fibroblasts (Faast et al., 2006). Thus, the use of ASC as nuclear donors is an increasingly interesting option because it may lead to an augmentation in the efficiency of animal cloning. However, establishing a simple method for the isolation and culture of MSC is an important determinant in making their use viable for such applications.

In conclusion, the present study supports the hypothesis that MSC can be isolated from bovine and buffalo adipose tissues. Additionally, these data provide evidence that MSC derived from bovine and buffalo adipose tissue can be cultured in vitro for many passages without losing their multilineage differentiation potential.

\section{ACKNOWLEDGMENTS}

Research supported by Conselho Nacional de Desenvolvimento Científico e Tecnológico (CNPq), Fundação de Amparo à Pesquisa do Estado de São Paulo (FAPESP), Fundação de Amparo à Pesquisa do Estado do Pará (FAPESPA), VALE S.A, Instituto Nacional de Ciência e Tecnologia em Células-Tronco e Terapia Celular (INCTC), and Universidade Norte do Paraná (UNOPAR).

\section{REFERENCES}

Berg DK, Smith CS, Pearton DJ, Wells DN, et al. (2011). Trophectoderm lineage determination in cattle. Dev. Cell 20: 244-255.

Bjornson CR, Rietze RL, Reynolds BA, Magli MC, et al. (1999). Turning brain into blood: A hematopoietic fate adopted by adult neural stem cells in vivo. Science 283: 534-537.

Bosnakovski D, Mizuno M, Kim G, Takagi S, et al. (2005). Isolation and multilineage differentiation of bovine bone marrow mesenchymal stem cells. Cell Tissue Res. 319: 243-253.

Bourzac C, Smith LC, Vincent P, Beauchamp G, et al. (2010). Isolation of equine bone marrow-derived mesenchymal stem cells: a comparison between three protocols. Equine Vet. J. 42: 519-527. 
Chacko E and Ranganathan S (2009). Genome-wide analysis of alternative splicing in cow: implications in bovine as a model for human diseases. BMC Genomics 10 (Suppl 3): S11.

Cheong HT, Takahashi Y and Kanagawa H (1993). Birth of mice after transplantation of early cell-cycle-stage embryonic nuclei into enucleated oocytes. Biol. Reprod. 48: 958-963.

Clark AJ, Ferrier P, Aslam S, Burl S, et al. (2003). Proliferative lifespan is conserved after nuclear transfer. Nat. Cell Biol. 5: 535-538.

Colleoni S, Donofrio G, Lagutina I, Duchi R, et al. (2005). Establishment, differentiation, electroporation, viral transduction, and nuclear transfer of bovine and porcine mesenchymal stem cells. Cloning Stem Cells 7: 154-166.

de Mattos Carvalho A, Alves AL, Golim MA, Moroz A, et al. (2009). Isolation and immunophenotypic characterization of mesenchymal stem cells derived from equine species adipose tissue. Vet. Immunol. Immunopathol. 132: 303-306.

Dominici M, Le Blanc K, Mueller I, Slaper-Cortenbach I, et al. (2006). Minimal criteria for defining multipotent mesenchymal stromal cells. The International Society for Cellular Therapy position statement. Cytotherapy 8: 315-317.

Faast R, Harrison SJ, Beebe LFS, McIlfatrick SM, et al. (2006). Use of adult mesenchymal stem cells isolated from bone marrow and blood for somatic cell nuclear transfer in pigs. Cloning Stem Cells 8: 166-173.

Gimble JM (2003). Adipose tissue-derived therapeutics. Expert Opin. Biol. Ther. 3: 705-713.

Jin HF, Kumar BM, Kim JG, Song HJ, et al. (2007). Enhanced development of porcine embryos cloned from bone marrow mesenchymal stem cells. Int. J. Dev. Biol. 51: 85-90.

Karp JM and Leng Teo GS (2009). Mesenchymal stem cell homing: the devil is in the details. Cell Stem Cell 4: 206-216.

Lee SL, Kang EJ, Maeng GH, Kim MJ, et al. (2010). Developmental ability of miniature pig embryos cloned with mesenchymal stem cells. J. Reprod. Dev. 56: 256-262.

Livak KJ and Schmittgen TD (2001). Analysis of relative gene expression data using real-time quantitative PCR and the 2(-Delta Delta C(T)) method. Methods 25: 402-408.

McCoy MK, Martinez TN, Ruhn KA, Wrage PC, et al. (2008). Autologous transplants of Adipose-Derived Adult Stromal (ADAS) cells afford dopaminergic neuroprotection in a model of Parkinson's disease. Exp. Neurol. 210: 14-29.

Meirelles FV, Birgel EH, Perecin F, Bertolini M, et al. (2010). Delivery of cloned offspring: experience in Zebu cattle (Bos indicus). Reprod. Fertil. Dev. 22: 88-97.

Miziara MN, Riggs PK and Amaral ME (2004). Comparative analysis of noncoding sequences of orthologous bovine and human gene pairs. Genet. Mol. Res. 3: 465-473.

Neupane M, Chang CC, Kiupel M and Yuzbasiyan-Gurkan V (2008). Isolation and characterization of canine adiposederived mesenchymal stem cells. Tissue Eng. Part A 14: 1007-1015.

Passier R and Mummery C (2003). Origin and use of embryonic and adult stem cells in differentiation and tissue repair. Cardiovasc. Res. 58: 324-335.

Pittenger MF, Mackay AM, Beck SC, Jaiswal RK, et al. (1999). Multilineage potential of adult human mesenchymal stem cells. Science 284: 143-147.

Raoufi MF, Tajik P, Dehghan MM, Eini F, et al. (2011). Isolation and differentiation of mesenchymal stem cells from bovine umbilical cord blood. Reprod. Domest. Anim. 46: 95-99.

Rodriguez AM, Elabd C, Amri EZ, Ailhaud G, et al. (2005). The human adipose tissue is a source of multipotent stem cells. Biochimie 87: 125-128.

Sanchez-Ramos J, Song S, Cardozo-Pelaez F, Hazzi C, et al. (2000). Adult bone marrow stromal cells differentiate into neural cells in vitro. Exp. Neurol. 164: 247-256.

Yamamoto N, Akamatsu H, Hasegawa S, Yamada T, et al. (2007). Isolation of multipotent stem cells from mouse adipose tissue. J. Dermatol. Sci. 48: 43-52.

Zhu Y, Liu T, Song K, Fan X, et al. (2008). Adipose-derived stem cell: a better stem cell than BMSC. Cell Biochem. Funct. 26: 664-675.

Zuk P, A, Zhu M, Ashjian P, De Ugarte DA, et al. (2002). Human adipose tissue is a source of multipotent stem cells. Mol. Biol. Cell 13: 4279-4295. 